\title{
Escabiasis costrosa imitando una acrodermatitis continua de Hallopeau
}

\author{
María S. Roldán-Franco ${ }^{1 *}$, Myriam J. Yat-Juárez de Nitsch ${ }^{2}$ y Helga M. Sarti ${ }^{3}$ \\ ${ }^{1}$ Instituto de Dermatología y Cirugía de Piel; ${ }^{2}$ Piel Saludable; ${ }^{3}$ Dermopatología Clínica e Histología de la Piel. Ciudad de Guatemala, Guatemala
}

\section{Resumen}

Introducción: La escabiasis costrosa (EC) es una variante poco común de sarcoptiosis clásica, altamente contagiosa. Las lesiones poseen una elevada concentración del ácaro Sarcoptes scabiei var hominis, lo que conlleva a un cuadro clínico más extenso que en la escabiasis clásica. Se observa principalmente en pacientes con algún tipo de inmunocompromiso y se relaciona con el síndrome de Down. Caso clínico: Se describe una paciente pediátrica con síndrome de Down quien presentó placas escamosas que afectaron la porción distal de los dedos, asociadas con distrofia ungueal e hiperqueratosis subungueal, por lo que se consideró acrodermatitis continua de Hallopeau como diagnóstico diferencial. Se realizó una biopsia tipo punch con lo que se llegó al diagnóstico de EC. La paciente recibió tratamiento sistémico con ivermectina vía oral y tratamiento tópico con crema hidratante y desonida al $0.1 \%$. Mostró mejoría clínica notoria dos semanas después de finalizar el tratamiento. Conclusiones: La EC es una variante prevalente en pacientes inmunocomprometidos y con síndrome de Down que fácilmente puede confundirse con patologías inflamatorias con alteración de la queratinización epidérmica. Este caso se considera una presentación atípica debido a la afección localizada en los dedos de las manos asociada con distrofia ungueal. El estudio histopatológico fue necesario para realizar el diagnóstico y descartar diagnósticos diferenciales.

Palabras clave: Escabiasis costrosa. Sarna noruega. Síndrome de Down. Acrodermatitis continua de Hallopeau.

\section{Crusted scabies mimicking an acrodermatitis continua of Hallopeau}

\begin{abstract}
Background: Crusted scabies (CS) is an uncommon, highly contagious, variant of classic scabies. Elevated concentrations of the mite Sarcoptes scabiei var. hominis are found in the skin lesions, which lead to a more exaggerated clinical picture than in classic scabies. This disease is mainly observed in patients with any kind of immunosuppression and relates to Down syndrome. Case report: A pediatric female patient with Down syndrome, who presented a crusty white plaque associated with nail dystrophy and subungual hyperkeratosis affecting the distal portion of the fingers is described. Because of these findings, the diagnosis of acrodermatitis continua of Hallopeau was considered. A punch biopsy was performed, attaining the diagnosis of CS. She received systemic treatment with oral ivermectin, topical treatment with emollient cream and desonide $0.1 \%$. Notorious clinical improvement was observed two weeks after finalizing treatment. Conclusions: CS is variant of scabies prevalent in immunocompromised patients and Down syndrome that can be easily confused with inflammatory pathologies with abnormal epidermal keratinization. This case is considered as an atypical presentation of the disease because
\end{abstract}

*María Sofía Roldán-Franco E-mail: mroldan@ufm.edu
Disponible en internet: 05-07-2019

Fecha de recepción: 30-01-2019 Fecha de aceptación: 20-05-2019 DOI: 10.24875/BMHIM.19000012
Bol Med Hosp Infant Mex.2019;76:198-202

www.bmhim.com 
of local affection of the fingers and nail dystrophy. The histopathological study was necessary to obtain the diagnosis and rule out differential diagnosis.

Key words: Crusted scabies. Norwegian scabies. Down syndrome. Acrodermatitis continua of Hallopeau.

\section{Introducción}

La escabiasis costrosa $(\mathrm{EC})$ es una variante rara y altamente contagiosa de la sarcoptiosis clásica, causada por el parásito Sarcoptes scabiei var hominis ${ }^{1-3}$. Es conocida también como sarna noruega, ya que fue descrita en 1948 en pacientes noruegos con lepra lepromatosa ${ }^{4}$. Se ha observado que la EC posee una mayor densidad del parásito mencionado, y alcanza miles o millones de ácaros en un paciente, en comparación con la forma clásica de la enfermedad, en la que solamente se encuentran docenas de este microorganismo'.

La EC es considerada por la Organización Mundial de la Salud como una enfermedad olvidada. Presenta una distribución preferencial entre la población pediátrica, lo cual refleja una mayor exposición al parásito o inmunidad deficiente en este grupo etario. La escabiasis afecta ambos sexos por igual y los principales factores de riesgo para la infestación son el hacinamiento, la pobreza, bajo estado nutricional, demencia, falta de vivienda e higiene deficiente ${ }^{5}$. La EC ocurre principalmente en pacientes con algún tipo de inmunocompromiso, como receptores de trasplante de órganos 0 infección por el VIH. Los pacientes con algún tipo de incapacidad física o mental, como parálisis, neuropatía sensorial, lepra o síndrome de Down (SD), también son susceptibles a esta enfermedad debido a la imposibilidad para percibir el prurito o estar incapacitados para rascarse ${ }^{5}$. La EC se caracteriza por placas hiperqueratósicas eritematosas o psoriasiformes, con escama amarillenta adherente. Puede haber presencia de fisuras sobre las placas, lo que favorece la infección bacteriana ${ }^{6}$. Existe afección ungueal, que se caracteriza por hiperqueratosis subungueal y compromiso de la lámina ungueal, y puede acompañarse de linfadenopatía, eosinofilia y niveles elevados de IgE (inmunoglobulina $E)$ e $\operatorname{lgG}^{1,2}$. La $E C$ puede ser generalizada 0 localizada en la piel cabelluda, cara, uñas y plantas. El $50 \%$ de los pacientes con EC no presentan prurito. Aunque el diagnóstico es clínico y complejo, se puede hacer uso de diferentes herramientas. La prueba de Muller o raspado de piel es el método diagnóstico más recomendado en la literatura, cuyo objetivo es examinar el espécimen bajo microscopia de luz y observar el ectoparásito. Otra prueba bastante práctica que ha quedado en desuso es la prueba de tinta china del surco, que consiste en la aplicación de tinta china o tinta de pluma fuente en un sitio sospechoso que después se frota suavemente. El exceso de tinta se limpia con alcohol, lo que hace visible el surco acarino: una línea ondulada llena de tinta a nivel del estrato córneo ${ }^{7}$. Sin embargo, en la EC no se observan signos característicos como en la sarcoptiosis clásica ${ }^{3,4}$.

La EC puede confundirse fácilmente con la psoriasis o pitiriasis rubra pilaris, y llevar a errores terapéuticos ${ }^{2,5}$. La dermatitis atópica, dermatitis herpetiforme, urticaria papular, tiña, impétigo y liquen plano son los principales diagnósticos diferenciales de la escabiasis clásica ${ }^{8}$. El tratamiento de la EC debe ser sistémico: se recomienda utilizar terapia oral en conjunto con la terapia tópica. En contraste, para la escabiasis clásica, el tratamiento tópico es la primera línea: el fármaco más recomendado es la permetrina al $5 \%$, aunque el crotamitón al $10 \%$, la ivermectina al $1 \%$ y el malatión al 0.5\% también se han utilizado con buenos resultados 5 . La terapia sistémica recomendada es dos dosis de ivermectina $(200 \mu \mathrm{g} / \mathrm{kg})$ de 8 a 15 días de separación entre ambas 1,9 .

Es necesario aislar al paciente por la alta infectividad del parásito, así como tener los cuidados necesarios para erradicar los ácaros de la vestimenta y objetos que podrían actuar como fómites.

\section{Caso clínico}

Paciente de sexo femenino de 9 años de edad con $\mathrm{SD}$, que acudió a consulta por prurito de 6 meses de evolución en las extremidades y el tronco. Al examen físico, se observó dermatosis diseminada a las axilas, tronco, genitales externos, glúteos y extremidades superiores, con predominio en los pulpejos de los dedos, caracterizada por múltiples pápulas de $0.2 \mathrm{~mm}$ aproximadamente, eritematosas, algunas excoriadas con costras hemáticas de bordes regulares mal definidos (Fig. 1). En los pulpejos del tercero y cuarto dedo de la mano izquierda y cuarto dedo de la mano derecha, se observaron placas queratósicas con escama amarillenta adherente, de aproximadamente $2 \mathrm{~cm}$ de diámetro, con bordes irregulares mal definidos. En las uñas de los dedos afectados se observó hiperqueratosis subungueal y onicólisis (Fig. 2). Se realizó una 


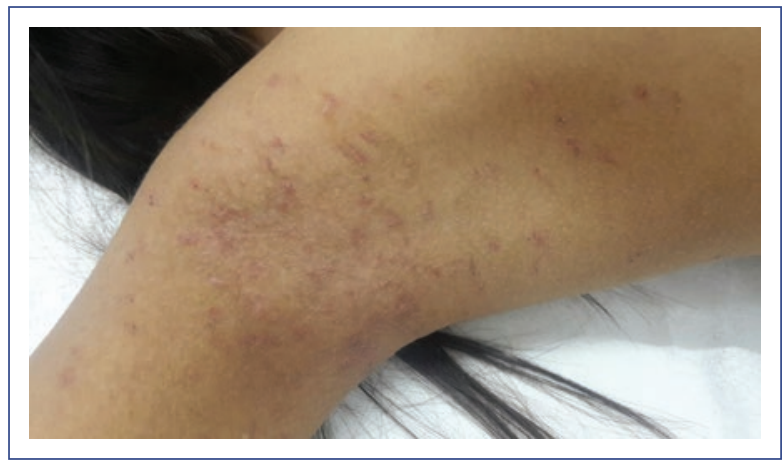

Figura 1. Múltiples pápulas eritematosas excoriadas a nivel axilar, algunas con costras hemáticas.

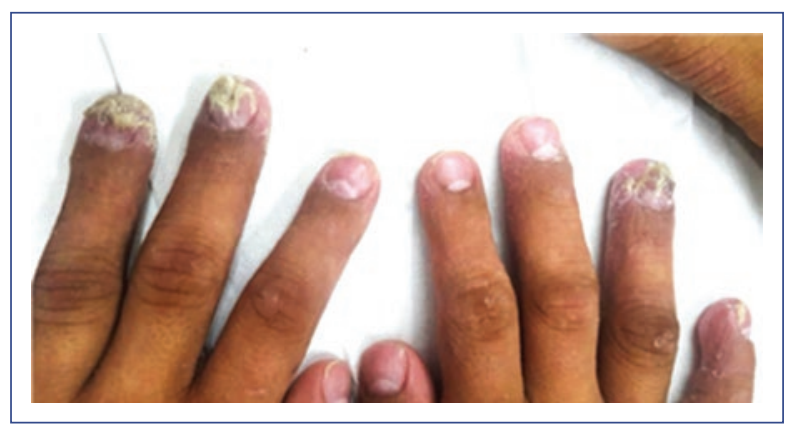

Figura 2. Placas queratósicas con escama amarillenta bien adherida, de bordes irregulares mal definidos, asociadas con hiperqueratosis subungueal y onicolisis.

biopsia de la placa queratósica en el tercer dedo de la mano izquierda. En espera de la confirmación histopatológica, se prescribió tratamiento tópico con emoliente y desonida al $0.1 \%$, debido a su baja toxicidad, para su aplicación en los pulpejos de los dedos afectados, además de dos dosis de ivermectina $(200 \mu \mathrm{g} / \mathrm{kg})$ vía oral en el primero y el décimo día. Se brindó un amplio plan educacional a la madre de la paciente para realizar las medidas higiénicas ambientales: el adecuado lavado y secado a altas temperaturas de la vestimenta, toallas y ropa de cama. También se prescribió tratamiento con permetrina al $5 \%$ en crema a los familiares que tuvieron contacto con la paciente.

El resultado histológico reveló una lesión papilomatosa con estrato córneo laminar compacto con hiperqueratosis, donde se observaron múltiples esqueletos de Sarcoptes scabiei; la epidermis con acantosis regular; en dermis papilar y reticular superficial, se observó infiltrado linfocitario inflamatorio perivascular (Fig. 3).

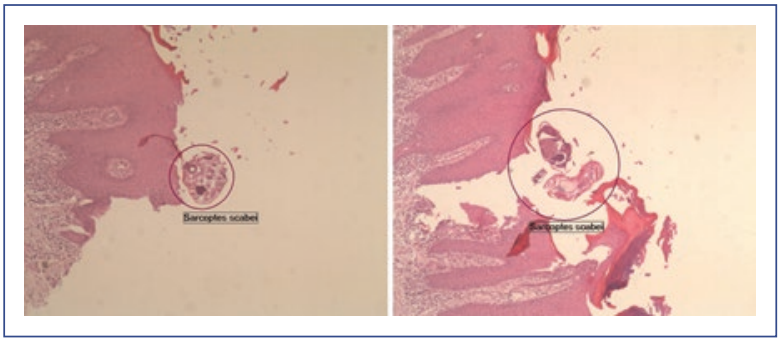

Figura 3. Esqueletos de Sarcoptes scabiei (tinción hematoxilina-eosina $10 x$ y $40 x$ ).

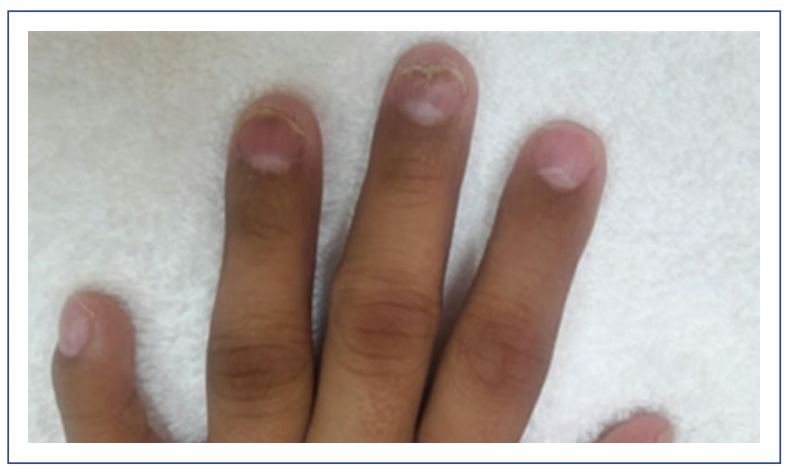

Figura 4. Ausencia de placas queratósicas a nivel de los pulpejos de los dedos. Mejoría clínica de las lesiones ungueales.

Dos semanas después de finalizar el tratamiento, la paciente presentó mejoría de dermatosis corporal, ausencia de placas queratósicas a nivel de los pulpejos de los dedos, mejoría clínica de las lesiones ungueales y disminución del prurito (Fig. 4).

\section{Discusión}

La EC es una variedad clínica de la sarcoptiosis, rara y altamente contagiosa, pobremente comprendida, que puede llegar a comprometer la vida del paciente. Se caracteriza por proliferación del parásito Sarcoptes scabiei: miles de estos microorganismos se pueden encontrar por gramo de piel. Clínicamente, se observan placas queratósicas, eritematosas con escama amarillenta que se correlacionan histológicamente con hiperqueratosis ${ }^{1,3}$. La afección puede ser localizada o diseminada, incluyendo áreas atípicas de la escabiasis clásica, como cara, orejas y piel cabelluda. La psoriasis generalizada es el principal diagnóstico diferencial de esta presentación atípica. La afección periungueal de la paciente presenta similitudes con la acrodermatitis 
continua de Hallopeau, por lo que esta enfermedad se consideró el principal diagnóstico diferencial a descartar. Sin embargo, es importante recordar otras dermatosis con afección ungueal en niños, como liquen plano y enfermedad de Darier. La acrodermatitis continua de Hallopeau es una enfermedad inflamatoria infrecuente que se presenta de forma aguda como una erupción pustular estéril en las falanges distales de las manos y los pies, con involucramiento del lecho ungueal, que evoluciona a placas eritematosas queratósicas en su forma crónica. También pueden presentarse onicodistrofia y osteólisis (llegan, incluso, a ser incapacitantes). Sin embargo, esta última es infrecuente en niños. Para confirmar el diagnóstico, es necesario un estudio histopatológico con hallazgos de una dermatitis psoriasiforme ${ }^{10,11}$.

Con respecto al pronóstico de la EC, se ha observado que la falla terapéutica o la reinfección son comunes $^{3}$. Actualmente se han descrito casos de EC en pacientes con uso de corticosteroides o terapias biológicas para enfermedades autoinmunes. Los pacientes en riesgo de presentar EC son aquellos con algún tipo de inmunosupresión o alteración neurológica: infección por $\mathrm{VIH}$, diabetes, receptores de trasplante de órganos, desnutrición. En el presente caso, se reporta una paciente con SD con historia de prurito y pápulas eritematosas de 6 meses de evolución. En la literatura se ha descrito una asociación entra la $E C$ y el SD ${ }^{3,6}$. Se ha contemplado que los pacientes con SD presentan una alta predisposición para infecciones de piel, lo cual puede deberse a xerodermia marcada, alteraciones a nivel de los linfocitos T e lgG. También se han descrito alteraciones en el mecanismo de rascado ${ }^{4}$. Las alteraciones a nivel de linfocitos $T$ pueden ser factor clave para el desarrollo de EC en estos pacientes, debido a que la respuesta inmunitaria contra el parásito se considera de tipo Th1.

Otro factor predisponente es el antecedente de esteroide tópico automedicado, el cual también se ha descrito como factor de riesgo para EC. Además de las lesiones de EC, la paciente también presentaba lesiones compatibles con escabiasis clásica de forma diseminada en el cuerpo. Dicho hallazgo podría explicar la presencia de prurito, el cual es raro en la EC.

El diagnóstico de la EC, o incluso de la escabiasis clásica, es problemático y puede complicarse por manifestaciones atípicas o sobreinfección bacteriana. El estudio histopatológico es confirmatorio. Yélamos, et al. reportaron una serie de cuatro casos en los que establecieron que el tiempo promedio para el diagnóstico acertado de EC en los pacientes fue de 7.8 meses $^{9}$, lo cual provoca complicaciones graves, como eritrodermia, alteraciones hidroelectrolíticas y sepsis ${ }^{9}$. El tratamiento de la EC debe de ser sistémico: de primera línea, puede utilizarse ivermectina $200 \mu \mathrm{g} / \mathrm{kg}$ vía oral o ivermectina intravenosa en casos graves. La terapia sistémica puede acompañarse de terapia tópica con crema de permetrina al $5 \%$ o malatión al $0.5 \%$ en loción, lo cual brinda buenos resultados ${ }^{2,12}$. El benzoato de bencilo se usa como escabicida, junto con la ivermectina o solo (en los casos de mujeres embarazadas o que estén lactando, infantes e incluso lactantes) ${ }^{12}$.

La paciente descrita en el presente reporte mostró mejoría clínica con una dosis de ivermectina a $200 \mu \mathrm{g} / \mathrm{kg}$ vía oral en el primer día y una segunda dosis en el décimo día.

Como conclusiones, se establece que la EC es una variante rara de la escabiasis, en la que puede haber una infestación de miles de ácaros por gramo de tejido. Es necesario tener la sospecha clínica presente cuando se trata de un paciente con factores de riesgo, como inmunocompromiso, SD, afección neurológica o uso inadecuado de esteroides tópicos de alta potencia. El cuadro clínico puede imitar otras patologías, comúnmente psoriasis. Antes de iniciar un tratamiento inmunosupresor en un paciente en riesgo, es recomendable realizar un examen físico exhaustivo, considerar una biopsia para la confirmación diagnóstica y sospechar de patologías que provocan inmunocompromiso, como cáncer, VIH o diabetes, en pacientes sin antecedentes médicos con EC. La reinfección es común mientras permanezcan los factores de riesgo.

\section{Responsabilidades éticas}

Protección de personas y animales. Los autores declaran que para esta investigación no se han realizado experimentos en seres humanos ni en animales.

Confidencialidad de los datos. Los autores declaran que han seguido los protocolos de su centro de trabajo sobre la publicación de datos de pacientes.

Derecho a la privacidad y consentimiento informado. Los autores han obtenido el consentimiento informado de los pacientes o individuos referidos en el artículo. Este documento obra en poder del autor de correspondencia.

\section{Conflicto de intereses}

Los autores declaran no tener ningún conflicto de intereses. 


\section{Financiamiento}

Ninguno.

\section{Bibliografía}

1. Golant AK, Levitt JO. Scabies: a review of diagnosis and management based on mite biology. Pediatr Rev. 2012;33:e1-12.

2. Arenas R. Dermatología. Atlas, diagnóstico y tratamiento. Ciudad de México: McGraw Hill; 2015. p. 451-4.

3. Mounsey KE, McCarthy JS, Walton SF. Scratching the itch: new tools to advance understanding of scabies. Trends Parasitol. 2013;29:35-42.

4. Manteroa NM, Jaimea LJ, Nijamina TR, Laffarguea JA, De Lillob L, Greesa SA. Sarna noruega en un paciente pediátrico con síndrome de Down. A propósito de un caso. Arch Argent Pediatr. 2013;111:e141-3.

5. Shimose L, Munoz-Price LS. Diagnosis, prevention, and treatment of scabies. Curr Infect Dis Reps. 2013;15:426-31.
6. Lehmberg J, Roper B, Omouryi EA, Monaliza E. Skin plaques mimicking psoriasis. J Pediatr. 2015;167:937.

7. Leung V, Miller M. Detection of scabies: A systematic review of diagnostic methods. Can J Infect Dis Med Microbiol. 2011;22:143-6.

8. Sánchez-Borges M, González-Aveledo L, Capriles-Hulett A, Caballero-Fonseca F. Scabies, crusted (Norwegian) scabies and the diagnosis of mite sensitization. Allergol Immunopathol (Madr). 2018;46:276-80.

9. Yélamos O, Mir-Bonafé JF, López-Ferrer A, Garcia-Muret MP, Alegre M Puig L. Crusted (Norwegian) scabies: an under-recognized infestation characterized by an atypical presentation and delayed diagnosis. J Eur Acad Dermatol Venereol. 2016;30:483-5.

10. Dini V, Barbanera S, Romanelli M. Efficacy of adalimumab for the treatment of refractory paediatric acrodermatitis continua of Hallopeau. Acta Derm Venereol. 2013;93:588-9.

11. Alorainy M, Alshaya M, Al-Rikabi A, Ayesh M, Alsaif F. Acrodermatitis continua of Hallopeau with bone resorption in an 8-year-old patient: a case report. Case Rep Dermatol. 2017;9:259-64.

12. Patel VM, Lambert WC, Schwartz RA. Safety of topical medications for scabies and lice in pregnancy. Indian J Dermatol. 2016;61:583-7. 